Economia e Sociedade, Campinas, Unicamp. IE. http://dx.doi.org/10.1590/1982-3533.2021v30n3art03

\title{
A Hipótese de Estagnação Secular nas teorias do crescimento econômico: um labirinto de inconsistências teóricas *
}

\author{
Vivian Garrido Moreira ** \\ Franklin Serrano ${ }^{* * *}$
}

\begin{abstract}
Resumo
O objetivo dessas notas é mostrar, que tanto na versão de A. Hansen quanto na de L. Summers, a argumentação sobre o problema da estagnação secular se faz baseada em fundamentos teóricos questionáveis, na medida em que parecem não serem construídos de forma coerente nem com a abordagem neoclássica para a teoria do crescimento, nem com os modelos heterodoxos de crescimento liderado pela demanda. Partimos da crítica, recentemente apresentada por F. Petri, ao uso incoerente da função investimento neoclássica em situações de desemprego persistente. Mostramos que o debate atual se conecta diretamente com o antigo debate sobre os dois problemas de consistência das teorias de crescimento a longo prazo levantados por R. Harrod. A análise nos permitirá entender melhor algumas questões do debate atual, como a polêmica Gordon-Summers sobre se as causas da recente tendência à estagnação nos países avançados deveriam ser atribuídas a fatores de oferta ou de demanda.
\end{abstract}

Palavras-chave: Crescimento liderado pela demanda; Estagnação Secular; Função investimento neoclássica.

\section{Abstract \\ The Secular Stagnation Hypothesis in the theories of economic growth: a maze of theoretical inconsistencies}

The purpose of this study is to show that, in both the Hansen and Summers versions, the secular stagnation hypothesis is based on questionable theoretical foundations that seem inconsistent both with the neoclassical approach to growth and with the heterodox models of demand-led growth. We build on F. Petri's recent critique of the incoherent use of the neoclassical investment function in situations with persistent labor unemployment, and show that the recent debate is directly connected with the old debate about the two problems raised by R. Harrod. The analysis allows us to understand some questions related to the current debate, such as the Gordon-Summers controversy on whether the causes of the recent stagnation tendencies in developed countries should be attributed to supply or demand factors.

Keywords: Demand-led growth, Secular Stagnation, Neoclassical investment function. JEL: O41, B22, B5.

\section{Introdução}

Em março de 1939, Alvin Hansen apontou em difundido artigo na American Economic Review, a possibilidade concreta de um processo de significativa estagnação da economia estadunidense, que denominou "estagnação secular". Recentemente Larry Summers $(2014 ; 2015)$ retomou com vigor esta ideia original, reconhecendo no Japão, nas economias europeias e em outras economias desenvolvidas, como a dos EUA, a possibilidade de ocorrência de algo bastante

\footnotetext{
${ }^{*}$ Artigo recebido em 13 de novembro de 2019 e aprovado em 5 de julho de 2021. O presente trabalho foi realizado com apoio da Coordenação de Aperfeiçoamento de Pessoal de Nível Superior - Brasil (CAPES) - Código de Financiamento 001.

** Pesquisadora de Pós-Doutorado do Programa de Pós-Graduação em Economia da Universidade Federal de Santa Catarina (PPGEco-UFSC), Florianópolis, SC, Brasil. E-mail: vivian_garrido@yahoo.com.br. ORCID: https://orcid.org/0000-0002-3326-4737.

${ }^{* * *}$ Professor associado do Instituto de Economia da Universidade Federal do Rio de Janeiro (IE-UFRJ), Rio de Janeiro, RJ, Brasil. E-mail: franklinserrano@gmail.com. ORCID: https://orcid.org/0000-0002-9981-9029.
} 
semelhante, com a abertura de um hiato significativo entre o produto potencial e o efetivo, levando ao desemprego persistente e a baixas taxas de crescimento por longos períodos de tempo.

O objetivo dessas notas é evidenciar um conjunto de inconsistências teóricas presentes numa análise mais atenta das versões de Hansen e de Summers da hipótese de estagnação secular. Entendemos que os autores não trabalham esta hipótese de forma coerente, nem com a abordagem neoclássica, nem com a abordagem heterodoxa de crescimento econômico. Como instrumento para realizar esta argumentação partiremos da crítica ao uso da função investimento neoclássica em situações de desemprego persistente de mão de obra recentemente apresentada por Petri $(2013 ; 2015)$. Mostraremos que, a despeito da atualidade deste debate, ele se conecta diretamente com o antigo debate sobre os dois problemas de consistência das teorias de crescimento a longo prazo levantados por Harrod $(1939 ; 1948)$. A partir deste esclarecimento dos problemáticos fundamentos teóricos da noção de estagnação secular, podemos compreender algumas questões que surgem no debate atual, como a polêmica Gordon-Summers (Gordon, 2015) sobre se as causas da recente tendência à estagnação nos países avançados deveriam ser atribuídas a fatores de oferta ou de demanda.

Na próxima seção apresentaremos sucintamente a hipótese básica de estagnação secular primeiro em Hansen e depois em Summers, mostrando também de que forma será feita sua conexão com os dois problemas de Harrod. Na seção 2 começaremos listando as quatro primeiras inconsistências teóricas, obtidas ao analisar a hipótese de estagnação secular a partir de um ponto de vista neoclássico do crescimento. $\mathrm{Na}$ seção 3 , apontaremos as outras quatro inconsistências, obtidas agora quando da análise da hipótese de estagnação secular a partir de um ponto de vista heterodoxo do crescimento. Encerra-se o artigo com algumas considerações finais sobre os resultados encontrados. Devido ao excessivo uso da expressão "Hipótese de Estagnação Secular" esta será abreviada, doravante, como "HES".

\section{Estagnação Secular e a conexão com os dois problemas de Harrod}

O artigo-referência para a retomada da HES (Hansen 1939) expõe como ponto comparativo, o que o autor entende como a condição predominante no séc. XIX até o início do séc. XX: um elevado índice de formação de capital per-capita, incluindo o longo período que se seguiu à revolução industrial e os esforços de guerra. Essencialmente, a tendência a uma estagnação secular se refere a um processo de recuperação difícil e sem força pelo qual passam as economias após a grande recessão de 30, que faz do desemprego algo relativamente persistente e tendo como principal causa uma redução no ritmo de formação de capital em relação aos períodos anteriores. Aparece também como causa central para a redução na taxa de crescimento do estoque de capital o próprio declínio na taxa de crescimento da população. Isto se daria por uma série de motivos, entre os quais, são mencionados que o menor crescimento da população desestimularia a construção civil (residencial), os bens de utilidade pública, de consumo essenciais etc. A principal consequência dessa estagnação é a dificuldade de manutenção do pleno-emprego dos recursos humanos. Além da população, são também mencionados o menor crescimento da produtividade do trabalho, das invenções, e da descoberta de novos recursos e territórios como elementos igualmente impeditivos do investimento num quadro de tendência à estagnação. 
Por outro lado, menciona que o pleno-emprego não pode ser atingido sem um volume de gastos com investimento adequado para "preencher o gap entre os gastos com consumo e o nível de renda que pode ser atingido quando todos os fatores são empregados" (Hansen, 1939, p. 5). Para a obtenção do pleno-emprego torna-se, portanto, importante o desenho de políticas fiscais mais permanentes, que reduzam a poupança de pleno-emprego da economia através do consumo do governo ou transferências de renda para os consumidores, ou então pelo aumento do investimento do setor público. Como se vê, de um lado o autor sublinha a dotação de fatores como limitante fundamental do processo de crescimento, mas de outro não se propõe a fazer uma análise marginalista dos mecanismos deste processo, capaz de gerar preços que sinalizem a escassez relativa desses fatores e impulsionem o emprego dos mesmos, como seria o caminho mais usual numa situação em que a restrição está na oferta, seja de mão-de-obra, seja de outros fatores. Seguindo o caminho oposto, o autor entende que o produto fica limitado pela demanda baseado na hipótese Keynesiana de que a taxa de juros, exogenamente determinada por forças monetárias $\left(r_{k}\right)$, seria positiva em termos reais, mas superior à taxa de juros natural $\left(\mathrm{r}_{\mathrm{n}}\right)$ (de pleno-emprego) e rígida para baixo, mesmo no longo prazo. Por conta dessa rigidez, a taxa de juros não atinge seu nível natural, isto é, não cai o suficiente, impedindo que seja realizado um aprofundamento do uso do fator capital. Ou seja, impedindo que a relação capital-produto (v) aumente o suficiente para o investimento se igualar à poupança de plenoemprego, o que só ocorre quando a taxa real de juros é igual à natural $\left(\mathrm{r}_{\mathrm{n}}\right)$, gerando uma relação capital-produto $v\left(r_{n}\right)$. Não obstante, dada a taxa efetiva $r_{\mathrm{k}}$, gera-se apenas a relação capital-produto $v\left(r_{k}\right)$, o que leva a um nível de investimento que está abaixo do que seria necessário para gerar plena utilização do capital e pleno-emprego, segundo a HES.

Larry Summers $(2014 ; 2015)$ retoma e sistematiza a tese anterior, a partir de um profundo desaquecimento econômico que marca os anos recentes, destacando-se uma taxa natural de juros (aquela que seria compatível com o equilíbrio de pleno-emprego) agora tendencialmente negativa em termos reais e uma inflação muito baixa/deflação. O problema agora não estaria numa taxa de juros resistente à baixa, mas na impossibilidade de que seu valor atinja um nível real positivo e, portanto, a economia não poderia atingir o pleno-emprego apenas através do uso da política monetária, mantendo-se estagnada. Efetivamente, as economias estagnadas se encontrariam nesta situação por conta de uma elevada propensão a poupar e uma baixa propensão a investir. Summers prossegue, mostrando que os principais fatores a influenciar as propensões a poupar e a investir seriam: baixo crescimento da população e da tecnologia, exatamente como em Hansen, e baixo preço relativo dos bens de capital junto com progresso técnico poupador de capital, significando queda de demanda por bens de capital (lado da curva de investimento); aumento histórico da desigualdade que aumenta a parcela da renda que vai para aqueles que têm maior propensão a poupar (lado da curva de poupança de pleno-emprego), fazendo com que haja relativamente mais poupança de pleno-emprego do que antes. A poupança de pleno-emprego muito elevada reflete, além da má distribuição de renda e da riqueza, uma espécie de saturação dos interesses no consumo em relação à renda, algo que poderia ser esperado em países que já alcançaram elevado grau de desenvolvimento. O investimento baixo reflete, por outro lado, um tipo de saturação das oportunidades de investimento, tanto pelo baixo crescimento da população, quanto pelo baixo crescimento da produtividade. Por isso, toda política de estímulo ao consumo privado ou de aumento de investimento público seria bem-vinda. 
Em suma, numa versão geral da HES, podemos dizer que a taxa de crescimento natural $\left(g_{n}\right)$ (igual à soma do crescimento da força de trabalho e da produtividade) é um primeiro limitador estrutural do processo de investimento, fazendo com que a posição da curva de demanda por investimento $(\mathrm{I}=\mathrm{f}(\mathrm{r}))$ fique muito afastada da posição da curva de poupança potencial $\left(\mathrm{S}^{*}\right)$. Isso impossibilita que a própria taxa de juros caia o suficiente até atingir seu nível natural, seja porque a economia cai, previamente, a partir de uma taxa de juros efetiva $r_{k}$, em armadilha de liquidez (Hansen) sendo a taxa de juros real natural $\left(\mathrm{r}_{\mathrm{n}}\right)$ neste caso, positiva porém muito baixa (Figura 1-A); seja porque a própria taxa natural seria negativa (Summers) (Figura 1-B). Assim, a economia opera com excesso de poupança potencial, ficando, supostamente, impedida de atingir o pleno-emprego e apresentando um quadro indefinidamente continuado de desemprego.

Figura 1A

Taxa de juros natural positiva e muito baixa

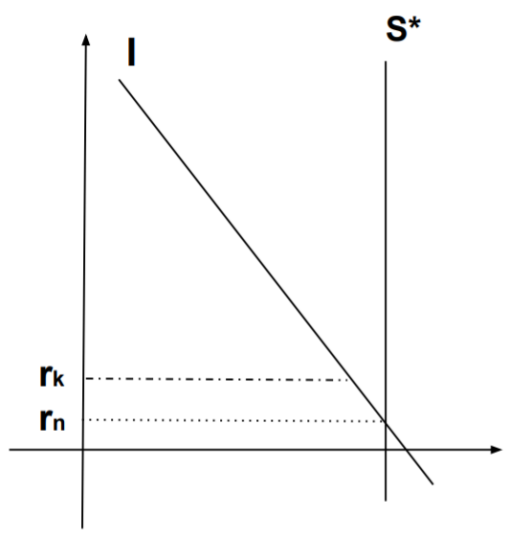

Figura 1B

Taxa de juros natural negativa

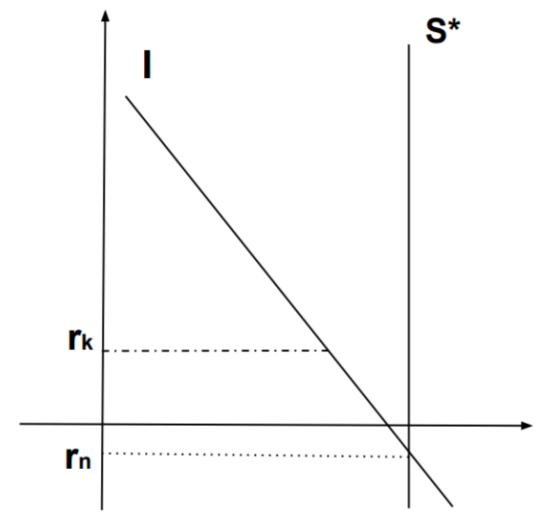

$\mathbf{r}_{\mathbf{k}}=$ taxa de juros real efetiva

$r_{n}=$ taxa de juros real natural

Para superar isso, destaca-se pelos proponentes da HES, a importância da política fiscal, utilizada como a fonte de demanda essencial para "fechar o hiato" entre o investimento privado e a poupança de pleno-emprego. Com isso, desloca-se para esquerda a curva de poupança potencial e recupera-se os níveis absolutos (positivos) da taxa natural de juros e a possibilidade de fazer política monetária, já que a HES mantém intacta a proposição tradicional da sensibilidade do investimento às taxas de juros. Outra possibilidade também para "recuperar" a taxa natural de juros seria um eventual efeito acelerador da política fiscal, aumentando o investimento e deslocando para a direita a sua respectiva curva.

Unindo esses argumentos de forma sintética e altamente simplificada, podemos reescrevê-los diretamente através das seguintes variáveis:

- propensão a poupar (s) "alta”;

- relação capital-produto (v), taxa de crescimento da força de trabalho (n) e da produtividade do trabalho (b), "baixos" 
O descompasso sugerido pela HES entre o crescimento da poupança de pleno-emprego e do investimento pode ser sintetizado nas variáveis acima. Para ver isso, primeiro é preciso considerar o argumento dos autores de que se o modelo crescesse equilibradamente e sem a hipótese de estagnação, o crescimento do estoque de capital ocorreria de forma diretamente proporcional ao crescimento do fator trabalho. Considerando que o volume de trabalho (em unidades de eficiência) cresce à taxa $(n+b)$, então, para que a o estoque de capital também cresça à $(n+b)$ mantendo a relação técnica capital-produto (v) ao longo deste processo, seria preciso que a parcela da poupança na renda(s) aumentasse para se igualar a $(n+b) \cdot v$, na medida em que é preciso $\mathrm{v}$ unidades de capital para cada 1 unidade produzida de $\mathrm{Y}$. Mas mediante o descompasso mostrado acima, essa igualdade não ocorre, de modo que: $s>(n+b)$. $v$. Ou simplesmente:

$$
s / v>(n+b)
$$

Mas a expressão $s / v$ é, nada mais, nada menos, que a taxa garantida do modelo de Harrod. Esta forma de apresentar o tema, criando uma importante aproximação entre a HES e uma questão elementar de crescimento, nos coloca em condições de perceber que, para além de um problema de política macroeconômica, a HES deve ser também analisada quanto à sua consistência com as teorias de crescimento econômico que lhe forem compatíveis. Assim, nas próximas páginas faremos uma discussão da HES, dissertando sobre como trabalhá-la em conexão com as soluções existentes dos "dois problemas" de Harrod $(1939,1948)$, tanto dentro da abordagem ortodoxa, quanto da heterodoxa do crescimento econômico, uma vez que a HES contém elementos de ambas as abordagens. Como é sabido que a condição para chegar à equação fundamental de Harrod envolve a igualdade entre investimento e poupança agregados quando o mercado de produto está em equilíbrio em condições de crescimento sustentado (steady state):

$$
\begin{aligned}
g=g_{K}=\frac{I}{K} & =\frac{S}{K} \quad=\frac{S}{Y} \frac{Y^{*}}{K} \frac{Y}{Y^{*}} \\
& =\frac{S}{v} u
\end{aligned}
$$

onde $s$ é a propensão marginal (e média) a poupar, $v$ é a relação técnica capital-produto potencial da técnica em uso, que chamaremos apenas de "relação capital-produto", $u$ é o grau de utilização da capacidade produtiva e $g_{k}$, a taxa de crescimento do estoque de capital (as demais variáveis, com suas conotações usuais). Se a economia crescer equilibradamente, $u=$ normal $=1$, e chega-se à equação fundamental de Harrod, que, no modelo completo também será igual, em condições de equilíbrio, à taxa de crescimento natural $g_{n}$ :

$$
g=g_{w}=\frac{s}{v}=g_{n}
$$

Mas a imposição de $u=1$ apenas indica que quando a economia cresce equilibrando demanda e geração de capacidade produtiva, o investimento cresce à taxa $s / v$, a taxa garantida. Como as variáveis da taxa garantida são exógenas não há qualquer motivo para uma coisa ser igual à outra e, logo, para $u=1$. E menos ainda para que a taxa garantida seja igual à taxa natural de crescimento. Vale lembrar que o primeiro problema de Harrod refere-se à improbabilidade de que a economia cresça à taxa de crescimento natural. Se a taxa de crescimento efetiva for, temporariamente, menor que a natural, isso resulta numa taxa de desemprego aberto num nível positivo e persistente 
$(1-L / N)$ (onde L é o nível de emprego e $\mathrm{N}$ o tamanho da oferta de trabalho). Já uma taxa de crescimento efetiva permanentemente menor que a natural levaria a taxas de desemprego crescentes ao longo do tempo. O segundo problema de Harrod, refere-se à improbabilidade de que a economia cresça à taxa garantida. Adicionalmente, no caso específico do segundo problema, ocorre a chamada instabilidade fundamental, porque qualquer mero desvio inicial do grau de utilização normal é reforçado sucessivamente pelo próprio investimento, uma vez que este é todo induzido pelo mecanismo do acelerador ou princípio de ajuste do estoque de capital ${ }^{1}$.

Para finalizar esta seção, esclarecemos que toda a investigação que se seguirá, tanto da análise pela via ortodoxa, quanto pela via heterodoxa da HES, será feita a partir de duas condições muito sucintas, mas que são, ao mesmo tempo, as duas condições centrais para a ocorrência da estagnação secular, e que se reportam também aos dois problemas de Harrod. Para isso:

i) a economia precisa gerar uma taxa de desemprego aberto positiva e persistente (subutilização da mão-de-obra e conexão com o primeiro problema de Harrod).

ii) a taxa de crescimento investimento (e da economia) precisa ficar abaixo da taxa garantida e seu nível ser menor que nível da poupança potencial de plena capacidade (subutilização da capacidade produtiva e conexão com o segundo problema de Harrod).

\section{Inconsistências da hipótese de estagnação secular a partir da teoria de crescimento neoclássica}

Vamos proceder esta análise com base no modelo neoclássico canônico de Solow (1956), uma vez que os elementos neoclássicos da HES são plenamente contempláveis por este modelo. Nele, utiliza-se uma função de produção do tipo Cobb-Douglas, sendo $a$ a participação do trabalho no produto, $(1-a)$ a participação do capital, A a produtividade total dos fatores, $\mathrm{B}$ um índice da eficiência específica do fator trabalho e $\mathrm{N}$ o volume total de mão-de-obra disponível. A economia, com juros reais e salários reais perfeitamente flexíveis tende ao nível de produto Y, de pleno-emprego tanto do capital disponível quanto do trabalho, como a seguir:

$$
Y=F(K, L B)=A K^{a} N B^{1-a} \quad(4) \quad \text { com } a<1 \text { e }[a+(1-a)=1]
$$

Como a soma dos coeficientes de participação dos fatores no produto é igual a 1, a função apresenta retornos constantes de escala, enquanto cada fator apresenta retornos marginais decrescentes ${ }^{2}$.

Para os nossos propósitos específicos será interessante apresentar os resultados do modelo neoclássico de crescimento de uma forma distinta da tradicional, chamando atenção para suas hipóteses implícitas sobre o comportamento da demanda por investimento e consequentemente para o crescimento da demanda agregada. Neste sentido é importante notar que Solow usa implícita, mas necessariamente a função investimento (líquido) neoclássica tradicional, na qual o investimento faz

(1) O princípio do ajuste do estoque de capital nesta discussão de Harrod pode ser visto em Serrano, Freitas e Bhering (2019).

(2) Estamos supondo que a economia só usa capital circulante. No caso da teoria neoclássica existe uma série de problemas analíticos complicados na relação entre a demanda pelo estoque de capital e fluxo de investimento, que não serão discutidos aqui, uma vez que a teoria neoclássica do capital (e de sua depreciação) só é realmente rigorosa no caso extremo onde existe apenas capital circulante (e aí a curva de demanda por capital é idêntica à demanda por investimento bruto) e este é homogêneo com o produto (ver Garegnani, 19789; Petri, 2004). Se tais dificuldades adicionais forem introduzidas isso só reforçaria as críticas apresentadas neste artigo. 
a economia se ajustar ao estoque de capital desejado derivado da função de demanda para o fator capital. A posição da curva de demanda por capital é afetada pela quantidade dos outros fatores empregados na produção, no caso o trabalho, e pela eficiência deste. E a inclinação depende da taxa real de juros, já que por conta da possibilidade de substituição de fatores sempre será lucrativo usar mais capital mesmo com uma quantidade empregada de trabalho dada, ou seja, com uma produtividade marginal do capital decrescente, contanto que a taxa de juros caia o suficiente. Numa economia em crescimento, o crescimento do estoque de capital desejado, $g_{k}$, vai então depender de dois elementos: do tamanho inicial e taxa de crescimento da força de trabalho e de sua produtividade (que deslocam a curva de demanda por capital) (expressão entre colchetes) e da taxa de variação da relação capital-produto $\mathrm{v}$ (segundo termo do lado direito) (que por sua vez responde inversamente a mudanças na taxa de juros), conforme a equação (5):

$$
g_{k}=\left[\left(1-\frac{L}{N}\right)+g_{n}\right]+\frac{\Delta v}{v}
$$

Para entender melhor o significado desta equação vamos começar com a expressão entre colchetes. Sendo, N o total de mão-de-obra economicamente ativa e L o total empregado, temos que L/N será o percentual empregado da população ativa e $\left(1-\frac{L}{N}\right)$ a taxa de desemprego; esta corresponde também ao tanto que deve crescer o emprego para zerar o nível de desemprego, a partir de um dado estoque inicial de $\mathrm{N}$. A medida em que o emprego aumenta, $\mathrm{L}$ se aproxima de $\mathrm{N}$ e $\mathrm{L} / \mathrm{N}$ tende a $1, \log o\left(1-\frac{L}{N}\right)$ tende a zero e o desemprego é zerado em nível; a partir daí, o crescimento do estoque de capital cresce acompanhando o crescimento da força de trabalho à mesma taxa, mantendo continuamente o pleno-emprego.

Já a expressão do segundo termo da direita mostra a variação da relação capital-produto, v, que varia com a taxa de juros. No caso em discussão, após o pleno-emprego, isto é, esgotado o fator trabalho (que é mais escasso na abordagem neoclássica) - que é captado assim que o termo entre colchetes se iguala a $g_{n}-$ a acumulação de capital se fará apenas com a elevação de v, isto é, intensificação da relação capital-produto, permitida pela queda da taxa de juros até seu nível natural. Assim, antes de chegar nesse ponto, a elevação do uso do fator capital se dá em consonância com o aumento do uso do fator trabalho (veremos isso com mais detalhe na próxima subseção, mas trata-se de um deslocamento da curva de investimento para a direita), mantendo $\mathrm{K} / \mathrm{L}$, e, portanto, $\mathrm{K} / \mathrm{Y}$, aproximadamente constante. Então, antes do pleno-emprego, ceteris paribus, como a razão K/L não varia de forma relevante, a elevação do uso de K se dá, via de regra, com juros constantes. Só depois de atingido o pleno-emprego é que realmente fica evidente o princípio da substituição, através do uso de proporções variáveis entre os fatores, com a variação recorrente da razão K/L e, portanto, de K/Y, até o esgotamento da poupança potencial (plena-capacidade). Isso porque, em condições de livremercado é a partir deste ponto que o excesso de oferta do fator capital (poupança potencial) se torna evidente, pressionando assim o seu preço (taxa de juros) para baixo, já que antes deste ponto, o excedente temporário de mão-de-obra não permitia que os retornos marginais ao capital em uso fossem decrescentes ${ }^{3}$.

(3) Mais sobre a explicação deste mecanismo será abordado a seguir na "inconsistência 1". 
Note que, como a taxa de crescimento do estoque de capital tende ao longo do tempo a se ajustar à taxa de crescimento desejado do estoque de capital temos que $g_{i}=g_{k}{ }^{4}$. Note também que, se a taxa de desemprego for inicialmente positiva, o ajuste para o pleno-emprego fará com que a taxa de crescimento da força de trabalho efetivamente empregada (em unidades de eficiência) seja temporariamente maior do que a taxa natural de crescimento e as duas taxas só serão iguais quando for atingido o pleno-emprego.

Há um aspecto muito revelador sobre a teoria de crescimento neoclássica nesta equação (5). A expressão entre colchetes evidencia o meio através do qual o crescimento do investimento garante o pleno-emprego do trabalho: com salários flexíveis, qualquer que seja o nível inicial e a taxa de crescimento da mão-de-obra e de sua eficiência, o crescimento do estoque de capital desejado e do investimento se ajustará a esta, absorvendo-a completamente (note que como todo o consumo é induzido a taxa de crescimento da demanda agregada g é igual a taxa de crescimento do investimento). Alcançado o pleno-emprego, resta mostrar como atingir o pleno uso da capacidade (estoque de capital instalado). Aí é que entra o primeiro termo da direita, que evidencia o meio através do qual o investimento se ajusta à poupança potencial: com taxas de juros flexíveis, a variável $v$ será tal que toda a poupança "disponível" seja absorvida, ou seja tudo que não for consumido, será investido; em outras palavras este termo garante a Lei de Say. Ou seja, esta equação norteia o caminho para atingir os dois resultados centrais de longo prazo da teoria do crescimento neoclássica: lei de Say (pleno uso do capital) e o pleno-emprego do trabalho. Ao mesmo tempo, dá pistas de quais seriam os instrumentos neoclássicos para trabalharmos na resolução das condições (i) e (ii) para a ocorrência de estagnação secular elencadas no final da última seção e que estão conectadas também com os dois problemas de Harrod.

Agora que já vimos a determinação da demanda por capital, recuperemos a hipótese de que todo o consumo é induzido e o crescimento da demanda efetiva ficará dado por $g=g_{i}$. Este último resultado nos permite ver que, dada a hipótese sobre a determinação da demanda por investimento, caso a taxa de juros real esteja constante (o que implica na constância de $v=v_{-1}$ ), mesmo partindo de uma posição inicial com desemprego de trabalho, o investimento e a demanda agregada ao longo do tempo tenderão a crescer à taxa natural, porque o tamanho da força de trabalho e de sua produtividade aumentam o estoque de capital desejado pelas firmas. Neste caso:

$$
g=g_{i}=g_{n}=(n+b)
$$

O primeiro problema de Harrod fica assim resolvido, mesmo supondo, em acordo com a HES, uma taxa de juros rígida que torna inviável o ajuste da relação capital-produto, $v$. Por outro lado, substituindo a condição (6) na equação (2), vemos o ponto levantado pelo segundo problema de Harrod. Para que esta taxa de crescimento, $g$, se iguale à taxa garantida, que permitiria a utilização normal de toda a capacidade produtiva, é preciso haver plena flexibilidade da taxa de juros, que

(4) Lembrando (ver nota 2 acima) nossa hipótese simplificadora de que a economia só usa capital circulante, temos que nesse caso, em termos de investimento bruto, o crescimento do estoque de capital é simplesmente idêntico à variação do investimento bruto, pois a demanda por investimento bruto é idêntica à demanda por capital. Por outro lado, em termos de investimento líquido, a relação entre taxa de crescimento do estoque de capital desejado gk e a taxa de crescimento do investimento líquido gi será dada por : $(1+\mathrm{gi})=(\mathrm{gk} / \mathrm{gk}-1)(1+$ gk-1), onde gk-1 é a taxa de crescimento do estoque de capital no período anterior. Na equação acima vê-se que a discrepância entre as duas taxas só ocorre enquanto a taxa de crescimento do estoque de capital está se acelerando ou desacelerando e desaparece depois que a taxa de crescimento do capital desejado se estabiliza (ver Serrano; Freitas; Bhering (2020), nota 6, p. 10). 
viabilize o ajuste em $v$, de modo que o grau de utilização do capital se torne igual a 1 . Se isto não acontecer, não há como garantir a coincidência entre $g\left(=g_{n}\right)$ e a taxa garantida, que é aquela taxa de crescimento do investimento que permitiria também a absorção de toda a poupança potencial da economia e a própria utilização normal da capacidade produtiva total disponível:

$$
g_{n}=\frac{s}{v} u \quad \operatorname{com} u \neq 1
$$

Inconsistência 1 - utilizar a elasticidade-juros do investimento como relação relevante abaixo do pleno-emprego do trabalho

Vamos começar analisando a versão de Hansen e supondo diretamente a existência da última a partir das condições $(i)$ e (ii) elencadas no final da seção 1: presença de desemprego e investimento crescendo abaixo da poupança potencial.

De acordo com a teoria neoclássica, a elasticidade-juros do investimento define uma curva de demanda por um fator de produção, capital, inversamente relacionada com seu preço, taxa de juros. Neste caso, a taxa de juros de equilíbrio deste mercado, que é a taxa natural de juros, expressa o preço do capital como um índice de sua escassez relativa em relação ao outro fator (trabalho). A inclinação negativa da curva de investimento é necessária para garantir que os incentivos à acumulação (desacumulação) de capital ocorram sempre que houver excesso (escassez) de poupança, através do mecanismo de redução (aumento) da taxa de juros. Mas, como apontado por Petri (2013, 2015), o uso da função de demanda por capital e investimento neoclássica em situações fora do equilíbrio com pleno-emprego não é nada consistente. Isto porque a escassez relativa entre capital e trabalho é, efetivamente, captada através da posição da curva de investimento no referido gráfico, se situando tanto mais à direita quanto maior a dotação prévia de trabalho, uma vez que quanto maior o estoque de trabalho inicial, mais produtivo será o estoque de capital utilizado, de modo que a poupança potencial (dada) será "esgotada" para níveis mais altos de taxa de juros (ou seja a taxas naturais de juros maiores), correspondentes à maior produtividade marginal do capital (Figura 2).

Figura 2

Produtividade marginal do capital e taxa natural de juros para diferentes dotações de trabalho

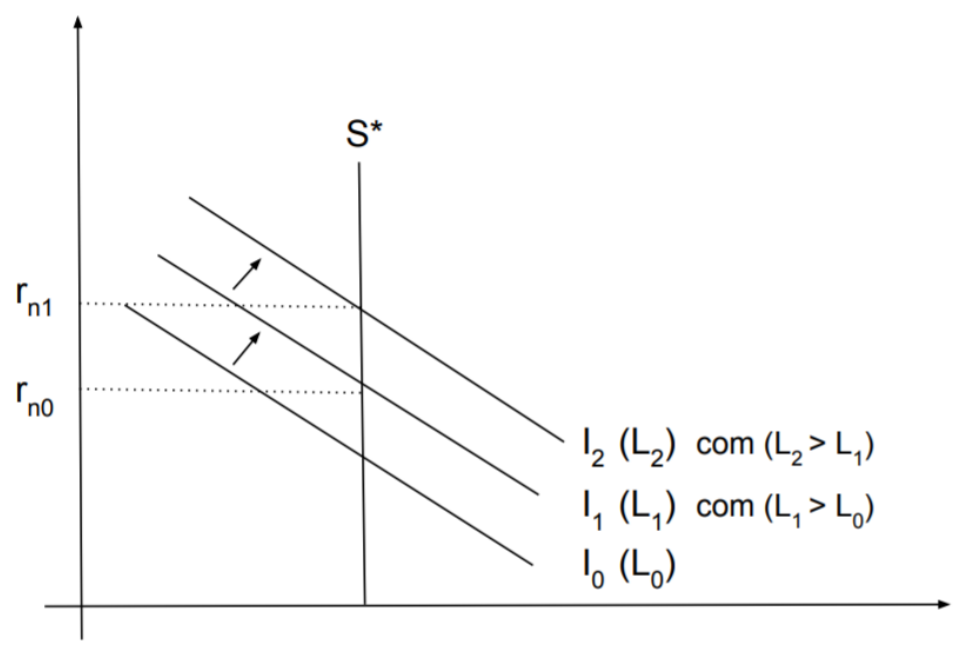


Então, a posição da curva de investimento e, consequentemente, a taxa natural de juros é dada com base no uso da dotação total de trabalho da economia. Por isso, enquanto há inicialmente um excesso de força de trabalho $(\mathrm{L}<\mathrm{N})$, há um correspondente deslocamento para a direita da curva de investimento e, embora neste caso a taxa de juros de equilíbrio esteja mudando, o investimento se mantém perfeitamente (infinitamente) elástico a uma dada taxa de juros efetiva qualquer (que porventura tenha sido fixada pelo Banco Central, por exemplo). Isto quer dizer que, numa situação em que a posição da curva de investimento ainda não é a posição final, isto é, a que esgota toda a dotação de trabalho, verifica-se não apenas o desemprego, mas também que a economia (o investimento) ainda não está na sua posição potencial de longo prazo, aquela na qual toda a poupança potencial é gerada (e ela é gerada quando a economia atinge a capacidade produtiva máxima permitida pela plena utilização dos fatores de produção) e absorvida pelo investimento. Ou seja, neste caso, as duas condições da HES, discutidas ao final da seção 1, são atendidas. O problema é que, de acordo com a teoria neoclássica, não há qualquer motivo para esta situação se manter, já que os incentivos econômicos deslocam a curva de investimento até aquela que estamos denominando sua "posição final".

Os retornos marginais ao capital só passam a ser decrescentes a partir do momento em que o trabalho se torna escasso e, a partir deste ponto, com a posição da curva de demanda por investimento dada, se quisermos que o estoque de capital cresça mais rápido que a força de trabalho, a taxa de juros tem que cair, momento a partir do qual a inclinação negativa da curva de investimento e, logo, uma movimentação ao longo da mesma, passa a refletir um comportamento economicamente relevante. Portanto, a intensificação do uso do fator capital, isto é, aumento de $v$, como resposta a uma menor taxa de juros só ocorre quando a quantidade de trabalho empregada está fixa, o que só ocorre sustentavelmente numa situação de pleno-emprego. Então, o máximo que se pode fazer a favor de Hansen sem contradizer este mecanismo neoclássico é "posicionar" a curva de investimento na posição de pleno-emprego e, a partir daí, com uma taxa de juros mantida, por qualquer motivo, acima da taxa natural, gerar a possibilidade de excesso de poupança, isto é, subutilização da capacidade (condição (ii) da HES), mas não desemprego de trabalho (condição (i) da HES). Caso contrário, tornase inviável para as políticas fiscal e monetária basearem-se numa curva de investimento regular negativamente inclinada em relação aos juros. Mas como os partidários da estagnação alegam que há desemprego estrutural como uma das características da própria estagnação, então a curva de investimento não pode estar em sua posição de longo prazo, logo não há efetividade para as referidas políticas, o que caracteriza uma inconsistência lógica da HES com a abordagem neoclássica.

Se há desemprego do trabalho, os incentivos à acumulação de capital continuam ocorrendo e deslocando a curva de investimento, independentemente das políticas do governo. Por conta deste tipo de mecanismo é que a posição da curva de investimento no modelo de Solow (cujo trabalho é escasso) é, efetivamente, a de pleno-emprego (equação 6), e assim tende a se manter, pois, a partir deste ponto, a taxa de crescimento do investimento, coeteris paribus, se manterá igual à taxa de crescimento natural (população mais produtividade). Neste caso, a taxa de investimento de equilíbrio de longo prazo só aumentará se a taxa de crescimento natural aumentar também. Mas, se a ideia de estagnação secular justamente é concebida porque a economia não está no pleno-emprego, então a curva de investimento não pode estar na mesma posição que estaria no modelo de Solow (valeria nossa equação 5). Mas, se a curva de investimento não pode estar naquela posição, então a taxa de 
acumulação não pode estar sendo restringida pela taxa de crescimento da força de trabalho. Porém, é exatamente isto que a HES aponta: a taxa de crescimento populacional (mais produtividade do trabalho, quando maior que zero), $g_{n}$, seria um dos principais fatores restritivos para a relativa estagnação do investimento. Trata-se de afirmar uma conclusão básica do modelo de Solow sem, no entanto, incorporar corretamente os elementos teóricos que constituem aquele modelo e que o justificam daquela forma. Para tanto, basta notar que um eventual aumento de $(n+b)$ não leva, para os proponentes da HES, ao contrário do modelo de Solow, a uma tendência de intensificação do uso de trabalho em relação ao capital, isto é, queda do coeficiente " $v$ ". Ou seja, a taxa garantida $(s / v)$ não é endógena neste caso, como o é no modelo de Solow.

Mas nossa discussão ainda não está completa. O que ocorre é que, ao longo desta subseção, pressupomos $g_{n}$ constante. Mas, na verdade, o caráter restritivo de $g_{n}$, e um dos problemas centrais no contexto da HES, tem a ver com a sua queda histórica e supostamente estrutural. Cabe então perguntar o que poderia acontecer, no longo prazo, com a taxa investimento, diante de uma queda permanente da taxa de crescimento natural. Seria possível, mantendo os princípios da teoria que estamos analisando, um processo de estagnação do crescimento do fator trabalho e sua eficiência gerar desemprego do trabalho e afetar (negativamente) o crescimento do investimento, configurando as condições $(i)$ e (ii) da HES?

Inconsistência 2 - utilizar a suposta queda histórica de $g_{n}$ como condição suficiente para gerar desemprego do trabalho.

Nosso objetivo aqui é desenvolver detalhadamente, seguindo a lógica marginalista, a hipótese de queda de $g_{n}$ e verificar se, em algum caso, seria possível brecar, reduzir ou prejudicar a taxa de crescimento do investimento com isso. Vamos partir de uma situação inicial de equilíbrio com investimento crescendo à taxa garantida e também igual à taxa natural, e supor uma redução exógena da taxa de crescimento da população e da produtividade do trabalho de $g_{n 0}$ para $g_{n 1}$. Esta redução de $g_{n}$ torna a taxa natural de crescimento menor do que a taxa garantida. Na visão neoclássica canônica, a solução devia ser uma queda suficientemente grande dos juros para provocar um aumento suficiente da relação capital produto, $v$. Isso ocorreria se os juros fossem flexíveis a baixa, o que estamos excluindo a partir da HES de Hansen, na qual cabe supor que a taxa real de juros da economia, encontra-se num nível $r=r_{k}$ e não pode ou não "consegue" mais cair em termos reais (independentemente do valor nominal fixado pelo Banco Central) ficando assim, persistentemente acima da taxa natural real de juros, ou seja, $r_{k}>r_{n}$.

A queda de $g_{n}$, ao tornar o trabalho ainda mais escasso em relação ao capital, inviabiliza a continuidade de absorção de mão-de-obra à taxa $g_{n 0}$, de modo que agora trabalho e capital crescerão à nova taxa $g_{n 1}$. Mas como a capacidade produtiva prévia comporta capital e trabalho crescendo à taxa $g_{n 0}$, no momento em que ambos passam a crescer a $g_{n 1}$, surge uma capacidade ociosa. Tal ociosidade nada mais é do que um excesso de poupança potencial em relação ao novo nível de investimento. Outra forma de verificar isto é, se a queda da taxa de juros não acontecer, ou não acontecer integralmente (até $r_{n}$ ), não ocorre o (suficiente) aumento do investimento (via $\mathrm{K}$ ) e consequentemente, também não ocorre o aumento da demanda imediatamente derivada deste aumento do investimento (que é dado pelo próprio investimento mais consumo induzido). Por isso a capacidade fica subutilizada. Finalmente, a subutilização do estoque capital instalado pode ser 
verificada, uma vez que a taxa garantida, $\frac{s}{v}$, dado que $v$ não será alterado e $s$ é constante, está fixada num nível que agora é maior do que a taxa natural, já que esta última caiu. ${ }^{5}$ Nesta situação, as taxas natural e efetiva se manterão iguais e menores do que a taxa garantida.

Antes: $\left(\frac{s}{v} \cdot u\right)=\frac{s}{v}$ pois $u=1=$ normal

Depois: $\left(\frac{s}{v} \cdot u\right)<\frac{s}{v}$ pois $u<1$

$$
u=\frac{g_{n 1}}{\frac{s}{v}}<1 \text { pois } g_{n 1}<\frac{s}{v}
$$

Mas é fundamental notar que não ocorre, neste esquema neoclássico, nenhum desemprego da força de trabalho pois o estoque de capital desejado, o investimento, a demanda agregada e o produto crescerão todos a taxa mais baixa $g_{n 1}$. Mas a força de trabalho e/ou sua produtividade está também crescendo a esta mesma taxa natural mais baixa $g_{n 1}$. Embora o investimento fique abaixo da poupança potencial, e isto está plenamente de acordo com o que propõe a HES, continua absorvendo toda a força de trabalho. Nos termos da equação (5), embora tenha havido a quebra da lei de Say (do pleno uso do capital), não há quebra do pleno-emprego. Ou, simplesmente, a taxa de crescimento do investimento será $g_{n 1}$ mas não será $\frac{s}{v}$. Curiosamente, a redução da taxa natural, mesmo com a taxa de juros real rígida, levaria apenas à subutilização do capital, mas não do trabalho. Neste caso, mesmo acrescentando uma queda permanente da taxa de crescimento natural, chegamos ainda à mesma conclusão que havíamos chegado quando discutimos a inconsistência anterior: não conseguimos manter, simultaneamente, as condições (i) e (ii) da HES, mas apenas a condição (ii). Então este é um primeiro ponto importante para "limpar o terreno" do que realmente está sendo tratado como estagnação secular: crescer abaixo da poupança potencial não implica gerar desemprego do trabalho se mantivermos todos os outros parâmetros e hipóteses neoclássicas sobre a função investimento. A estagnação de Hansen, portanto, geraria, no máximo, capacidade ociosa, mas não desemprego.

Se pudéssemos, livremente, lançar mão da solução neoclássica para tal situação, esta seria simplesmente, como sempre, um aumento suficientemente grande de $v$, mas isso só poderia ocorrer se os juros fossem flexíveis a baixa, o que estamos excluindo por hipótese. Qualquer intensificação do uso de capital (absorção da poupança) implica em produto marginal decrescente desse capital (dada a taxa de crescimento da força de trabalho) e só seria economicamente vantajoso fazer isto se a taxa de juros caísse em proporção com a queda do produto marginal do capital.

A pergunta que nos cabe fazer agora é: mas e se a taxa de juros fosse perfeitamente flexível, porém a taxa natural de juros fosse negativa, como proposto por Summers, então poderíamos conceber, pelo menos em parte, a HES?

(5) É válido notar que não é contraditório, embora possa parecer, que quando a relação técnica capital-produto aumenta, o estoque de capital fica normalmente utilizado e, justamente quando a relação capital-produto não aumenta é que o estoque de capital fica subutilizado. 
Inconsistência 3 - propor uma taxa de juros natural negativa como posição de equilíbrio estável de longo prazo

Vamos agora adentrar na argumentação de Summers, cujo ponto central, como vimos, é a proposição de uma taxa natural de juros negativa. Os bancos centrais não conseguiriam reduzir a taxa de juros nominal o suficiente para atingir o valor da taxa real natural negativa. $O$ problema teria a ver com o chamado limite inferior zero para a taxa de juros nominal $(i)$, fixada pelos bancos centrais num contexto em que a inflação $(p)$ é positiva, mas muito baixa. Assim, a taxa de juros real, dada por $(r=i-p)$, no caso de i cair a zero, ficaria pouco negativa se a inflação for muito baixa $(r=-p)$. Isso mostra que Summers tem que supor uma taxa natural real de juros substancialmente negativa $\left(r_{n}<-p\right)$, para que esteja ocorrendo a estagnação secular numa economia com taxas de inflação baixas, porém positivas. Em termos da nossa Figura 1-B, se a taxa natural for substancialmente negativa, por mais que o Banco Central tente, não consegue jogar a taxa efetiva de juros real até o nível natural, uma vez que só tem controle sobre o juro nominal, com nível mínimo de zero, e passa a depender de que a inflação seja bem mais elevada para que o juro efetivo real convirja até o natural.

Uma possibilidade aparentemente válida para esta configuração, fácil de prever depois do que já vimos, e compatível com os elementos propostos pela HES, seria uma muito baixa dotação de mão-de-obra (derivada de um $g_{n}$ baixo). Esta seria proibitiva para o uso de técnicas mais trabalhointensivas, posicionando a curva de investimento muito "à esquerda" em relação à curva de poupança potencial, fazendo com que a taxa natural de juros real resultante seja significativamente negativa. Como a taxa de crescimento demográfico e da produtividade seria baixa demais e, não havendo nenhum choque exógeno expansionista, não seria possível deslocar a curva I até a curva $\mathrm{S}^{*}$ dentro do quadrante positivo, tornando a taxa de juros negativa o único resultado de equilíbrio possível. Só que tal ideia, embora seja muito satisfatória para a teoria de Summers, não nos parece correta e constitui mais uma inconsistência, conforme discutiremos abaixo.

Dentro da abordagem neoclássica, com a qual estamos buscando coerência, o cruzamento da curva de investimento com a curva de poupança potencial só corresponderá ao equilíbrio estável de pleno-emprego da força de trabalho se ocorrer no quadrante positivo da taxa de juros. Isto porque, para o trecho onde a produtividade marginal do capital é negativa (taxa de juros negativa, quarto quadrante do gráfico de poupança e investimento), a produtividade marginal do trabalho, por seu turno, é positiva, o que levaria a técnicas mais intensivas em trabalho (havendo disponibilidade de mão-de-obra) ou simplesmente descontinuação do uso de parte do capital (não havendo disponibilidade de mão-de-obra), deslocando a curva de investimento para a direita (cima) até que a mesma cruze a curva de poupança potencial no quadrante positivo da taxa de juros.

Portanto, não é por coincidência que a taxa natural de juros num modelo de corte neoclássico, como o de Solow, por exemplo, se encontra sempre em um nível real positivo ${ }^{6}$, não fazendo sentido supor que a mesma é, e que, principalmente, tende a se manter, negativa num equilíbrio estável de longo prazo. Portanto, o máximo que se pode dizer sobre um equilíbrio com taxa natural de juros negativa é que se trata de um equilíbrio instável. Indicando o contrário, a situação proposta de estagnação econômica secular, por sua vez, sugere justamente uma condição estável continuada de

(6) Note que na função de produção Cobb-Douglas, pelo fato da elasticidade de substituição ser suposta igual a um, o produto marginal do capital declina assintoticamente mas nunca chega a ficar negativo. 
equilíbrio da taxa natural de juros num patamar negativo, o que, portanto, não é coerente com um esquema neoclássico ou mesmo de síntese neoclássica. Uma situação em que a taxa de juros real natural $r_{n}$ fosse zero ou negativa implica necessariamente que a economia está com um excesso crônico de capital em relação ao trabalho, e mais investimento reduziria o nível do produto potencial da economia. Em termos de nossas equações implicaria numa situação onde $g_{k}$ é inicialmente muito maior que $g_{n}$. Mas isso rapidamente levaria a uma forte redução do crescimento do estoque de capital, com investimento líquido negativo pois haveria um enorme incentivo para usar menos capital.

Formalmente $r_{n}<0$ poderia ocorrer persistentemente somente quando $\frac{\Delta Y}{\Delta K}<0$. Nesta situação de excesso crônico de capital em relação ao trabalho em unidades de eficiência $\mathrm{K} /(\mathrm{LH})$, a taxa de crescimento do estoque de capital, $g_{k}$ certamente seria menor que zero, o que implica, a partir da equação 5 , que $\frac{\Delta v}{v}$ tenderia não apenas a ser negativo, quanto, em valor absoluto, maior do que $\left(1-\frac{L}{N}\right)+g_{n}$. Assim, não só a taxa de crescimento, mas o próprio nível de investimento líquido e a taxa de crescimento do estoque de capital desejado se manteriam negativos pelo menos até o produto marginal do capital voltar a ser positivo. Note que mesmo que investidores tivessem acesso a fundos com taxas de juros reais negativas sempre seria bem mais lucrativo simplesmente não investir e repagar depois o empréstimo com lucro, do que investir em algo que reduziria o produto potencial das empresas que investissem. Mesmo dentro da abordagem neoclássica torna-se, portanto, muito difícil caracterizar tal situação como um equilíbrio de longo prazo (ou secular), pois a economia tende endogenamente a se afastar desta posição rapidamente.

Chegamos assim ao seguinte impasse: se quisermos manter a coerência da HES com a teoria neoclássica, teríamos que, primeiramente, excluir a hipótese de taxa natural de juros negativa (Summers). A partir disso, assumindo uma taxa natural positiva, partimos para a suposição de Hansen de rigidez da taxa de juros real. Porém, isto pressupõe que o investimento é negativamente relacionado à taxa de juros, e que o "único" problema é que a taxa de juros não cai a partir de certo ponto. Só que, conforme vimos na crítica de Petri $(2013$; 2015), para que esta relação negativa

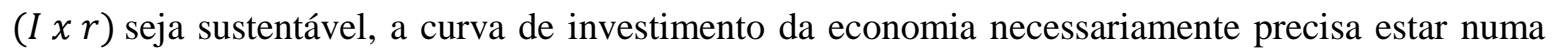
posição que implica pleno-emprego. Vimos ainda que, mesmo que se verifique uma queda continuada e histórica de $g_{n}$, tudo mais constante, a taxa de crescimento do investimento continuará sendo dada pela taxa de crescimento natural. Caímos, portanto, numa contradição: numa perspectiva coerente com os preceitos neoclássicos, a única situação na qual supostamente deveríamos descrever o desemprego junto a HES, seria uma situação que implica pleno-emprego.

$\mathrm{Na}$ realidade, com base na equação (5), já evidenciamos que o quadro acima proposto constitui uma quebra da lei de Say, ainda que de uma forma inusitada, já que o investimento, embora estivesse ainda sendo determinado pela taxa de crescimento natural, que é um elemento do lado da oferta, estava, entretanto, persistentemente abaixo da poupança potencial. Então, desse ponto de vista, dada a quebra da lei de Say, não seria mais adequado continuar analisando o problema através de alguma versão teórica marginalista e só o fizemos aqui para tentar gerar um quadro de estagnação secular coerente com os elementos marginalistas presentes na própria HES. Ou seja, estávamos assumindo uma imperfeição, qual seja, a rigidez da taxa real de juros, dentro de um arcabouço de modelo de crescimento neoclássico e mesmo assim não conseguimos encontrar ainda uma solução compatível com a HES. Neste ponto, já poderíamos partir para a análise da HES dentro da 
heterodoxia, mas cabe ainda a apresentação de uma última inconsistência que nos levará inevitavelmente a entrar pelo caminho heterodoxo.

Inconsistência 4 - supor o emprego do trabalho e o produto dados pela demanda e manter o investimento dado por um fator de oferta (taxa natural de crescimento)

Vamos manter a hipótese de rigidez da taxa real de juros (a la Hansen), mas agora supor adicionalmente que exista, ao menos no curto prazo, uma rigidez de preços e salários nominais na economia, o que torna o salário real rígido (por hipótese, acima do produto marginal do trabalho em pleno-emprego). Então, vamos começar retomando a equação $5\left\{g_{k}=\left[\left(1-\frac{L}{N}\right)+g_{n}\right]+\frac{\Delta v}{v}\right\}$ partindo de uma situação inicial de equilíbrio, considerando agora um (novo) salário real e, também, uma queda da taxa natural de $g_{n 0}$ para $g_{n 1}$, assim como fizemos anteriormente, para observar a trajetória do investimento.

Com a mudança na taxa $g_{n}$, o que se esperaria do novo equilíbrio seria uma queda de $g_{k}$ até o novo valor de $g_{n}$, isto é, até $g_{n 1}$, mantendo o pleno-emprego como antes. Mas a elevação e permanência rígida do salário real num patamar acima do produto marginal do trabalho em plenoemprego, reduz a demanda de trabalho até o ponto em que a produtividade marginal do trabalho se equipare ao novo salário real. Nos termos da nossa equação (5), com a rigidez suposta no salário real, o ajuste da demanda por trabalho ao novo salário reduz L e reduz $g_{k}$. Graficamente, a mudança na dotação de trabalho corresponde a um deslocamento para trás (esquerda) da curva de investimento, conforme vimos antes. A nova curva de investimento poderia se estabilizar nesta posição, desde que a taxa de juros caísse até o novo nível de equilíbrio que agora será mais baixo. Ou seja, o estoque de capital existente, que vinha sendo plenamente utilizado e que, em condições de equilíbrio continuaria plenamente utilizado, mesmo que passasse a crescer à nova taxa $g_{n 1}$, só poderá ser plenamente utilizado agora se a taxa de juros cair até seu novo patamar de equilíbrio. Mas como a taxa de juros também permanece rígida, então agora o estoque de capital ótimo vai ter que cair também até que sua produtividade marginal (que caiu devido à queda da dotação de trabalho) iguale a taxa de juros dada. Ou seja, verifica-se uma queda subsequente na demanda por capital, gerando, portanto, uma subutilização do estoque de capital então existente, o que, ao longo da cadeia produtiva, gera de novo mais desemprego... o que desloca novamente para trás a curva de investimento repetindo o ciclo e reforçando o processo na direção de recuo da demanda dos dois fatores (K e L). Evidentemente que com menos $\mathrm{K}$ e menos L do que antes, a produção cai. Não sendo possível recuperar o nível de produção através do uso adicional de nenhum dos dois fatores, o mecanismo de substituição então cai por terra inteiramente. Por conta da permanência dessas rigidezes nos preços dos dois fatores, não sobra mais nenhum mecanismo pelo lado da oferta para recuperar o nível de investimento. Isso joga a economia numa armadilha, de modo que o sistema não consegue se (re)estabilizar sob a nova taxa natural de crescimento a $g_{n 1}$ a cada nova queda da demanda por trabalho e, sequencialmente, por capital, levando a ulteriores reduções do crescimento do investimento, do grau de utilização e assim por diante.

Isto faz com que o produto efetivo seja determinado pela demanda agregada, e não mais pela taxa natural, eliminando todos os fatores de oferta na determinação do produto e assim abortando completamente a lei de Say. O princípio da instabilidade fundamental de Harrod voltaria a operar e a 
economia tenderia ao colapso e não apenas à estagnação. Mesmo que o efeito da taxa de crescimento efetiva do emprego sobre o crescimento do investimento fosse relativamente pequeno, como o ajuste está indo na direção errada, a economia fica cronicamente instável. Assim, o que está ocorrendo é que, quando a economia sai da posição de pleno-emprego, o crescimento do estoque de capital, $g_{k}$, passa a ser afetado pela taxa de crescimento da economia efetivamente ocorrida no passado recente $g_{-1}$. Formalmente:

$$
g_{k}=g_{-1}+\alpha u_{-1}
$$

que levaria a instabilidade para qualquer valor positivo de $\alpha{ }^{7}$

Agora a curva de demanda por capital se desloca para a esquerda sucessivamente, num processo cumulativo. Logo, voltamos ao segundo problema de Harrod. Veja que conseguimos evitar este problema mesmo com rigidez de preços em um dos mercados de fatores, mantendo a função de investimento neoclássica, mas quando introduzimos rigidez nos dois mercados, isso se torna inviável. Recolocado este problema, vamos discuti-lo na sequência, não só este, mas também o primeiro problema de Harrod na versão heterodoxa da HES, apontando as inconsistências geradas neste processo.

Estas várias inconsistências ilustram bem o dilema apontado por Petri $(2013,2015)$ de todos os que usam a função investimento neoclássica. De um lado, se for feita a hipótese de preços e salários nominais (e, portanto, salários reais) flexíveis como no modelo de Solow, a economia é levada ao pleno-emprego pelo deslocamentos para a direita da função de demanda por capital (curva de investimento), o que torna a taxa natural de crescimento o determinante central do crescimento do investimento a longo prazo. A outra opção é supor rigidez nominal de salários e preços gerando desemprego. Só que nesse caso a demanda por capital se desloca para a esquerda, e, na ausência de juros flexíveis, isto tende a gerar um processo do tipo acelerador-multiplicador instável.

\section{Inconsistências da hipótese de estagnação secular a partir da abordagem heterodoxa}

Nossa alternativa agora para tentar tornar robusta a HES é passar a abordá-la dentro da análise geral heterodoxa do crescimento (pós-keynesiana, neokaleckiana, sraffiana etc.). Ou seja, cabe agora interpretá-la em coerência com os modelos de crescimento liderado pela demanda, e averiguar se há melhor aderência de suas hipóteses a alguma das linhas de pesquisa existentes nesta grande área. A priori isto parece tanto possível como razoável, já que, a despeito dos muitos elementos ortodoxos utilizados pelos proponentes da HES, temos também vários heterodoxos, como a existência de desemprego involuntário como um fenômeno persistente, a centralidade da política fiscal (e, sob certas condições, da política monetária) e da expansão da demanda de uma forma geral para causar a expansão do produto e, também o papel, direto ou indireto, dessas políticas sobre o próprio investimento. ${ }^{8}$ Todavia, encontramos também problemas analíticos ao checar a consistência de uso da HES dentro desta abordagem, conforme veremos a seguir.

(7) Para prova formal da instabilidade fundamental de Harrod ver Serrano, Freitas e Bhering (2019)

(8) É importante ressaltar que, embora declaradamente o produto seja liderado pela demanda na hipótese de estagnação secular, não é evidente que o crescimento também seja liderado pela demanda. Esta é uma tentativa nossa de interpretação, para encontrar um caminho coerente de análise, uma vez que o caminho neoclássico do crescimento foi problemático. 
Inconsistência 5 - manter a relação inversa juros-investimento com fatores de produção complementares

Ao contrário da abordagem marginalista, a abordagem heterodoxa de um modo geral é bem mais heterogênea, de modo que precisamos elencar elementos relevantes dentro da HES para entender a partir de qual linha vamos analisá-la. O mais importante destes elementos é o horizonte de longo prazo, já que estamos diante de um processo de acumulação de capital. Dentro das teorias do crescimento econômico heterodoxas, além do próprio modelo de Harrod, encontramos destacadamente os modelos da linhagem de Cambridge, os neokaleckianos tradicionais com grau de utilização endógeno e os do tipo supermultiplicador (ver Lavoie, 2014, cap. 6). Para nossos fins vamos considerar apenas os modelos que não pressupõem restrição de oferta, pois estamos pensando em modelos nos quais tipicamente o crescimento é liderado pela demanda. Restam então os modelos em que o crescimento é liderado pelo componente autônomo do investimento (o tipo neokaleckiano tradicional) e os do tipo supermultiplicador onde o crescimento é liderado pelo componente de gastos autônomos que não criam capacidade (proposto por sraffianos e atualmente usado por alguns neokaleckianos), no qual o investimento agregado é induzido e segue o princípio do ajuste do estoque de capital ${ }^{9}$.

De maneira razoavelmente homogênea, essas linhas de pesquisa, em contraposição à ortodoxia, apontam que: i) no lugar de uma determinação simétrica da distribuição funcional, originada por funções de oferta e demanda de fatores, ocorre uma determinação assimétrica e exógena que se dá por forças políticas e institucionais, sendo fortemente marcada pelo poder de barganha dessas classes sociais; ii) não há nenhum mecanismo de ajuste de mercado que garanta uma relação entre intensidade de uso de um fator com seu preço relativo (salário, taxa de juros) e, logo, nenhuma relação destes preços com uma suposta produtividade marginal destes fatores. Com base em $(i)$ e (ii), chega-se a: (iii) não há qualquer tendência automática ao pleno-emprego da força de trabalho.

A partir disso, devemos assinalar que o primeiro problema de Harrod, acabará sendo "resolvido" de forma bem mais afinada entre os heterodoxos. A heterodoxia, de um modo geral, rejeita a noção de que a força de trabalho seja escassa, especialmente (mas não apenas) nos países em desenvolvimento. Isto ocorre através de uma série de processos que alteram endogenamente, na equação (1), os valores de " $n$ " - variação do tamanho do setor informal e dos níveis de desemprego disfarçado, mudanças na taxa de participação de diferentes grupos sociais bem como migrações internas e internacionais, ou "b" - a necessidade de mão de obra é em parte reduzida pelo crescimento da produtividade que é visto como parcialmente endógeno e função da própria acumulação de capital, devido a economias de aprendizado, progresso técnico incorporado nos bens de capital e retornos crescentes de escala. Portanto, é a taxa de crescimento natural que tende a se ajustar à efetiva, não o contrário, via variações endógenas no ritmo efetivo de crescimento da força de trabalho e sua produtividade, que se adaptam tanto "para mais" quanto "para menos" de acordo com as necessidades da acumulação de capital. Assim, apesar da existência de níveis persistentes de taxa de desemprego aberto, nesta visão, em geral, a taxa natural de crescimento acaba se ajustando à taxa de crescimento

(9) Para a análise das semelhanças e diferenças entre estes modelos ver Serrano e Freitas (2017). 
de longo prazo da economia (Cesaratto; Sitrati; Serrano, 2003; Deleide; Mazzucato, 2017; Nah; Lavoie, 2017; Fazzari; Ferri; Variato, 2017). Ou seja:

$$
g_{n}=n+b \rightarrow g
$$

Como o trabalho não é visto como escasso, o produto potencial da economia é limitado basicamente pelo estoque de capital acumulado e sua eficiência. Neste caso, o crescimento desta capacidade produtiva vai depender crucialmente da evolução do investimento. Na medida em que a mão-de-obra se ajusta às necessidades de produção e ao estoque de capital existente, o trabalho, ao contrário das teorias neoclássicas, deixa de atuar como substituto e passa a atuar como complementar ao capital. Denotando o coeficiente de trabalho por unidade de produto por 1 , temos que $K / v$ menor que $\frac{N}{l}$, e:

$$
Y^{*}=\min (K / v, N / l)
$$

Como consequência disso, surge uma descontinuidade na relação entre preço e intensidade de uso dos fatores, desaparecendo a relação inversa e sistemática que anteriormente existia entre essas variáveis. O limite dado pela escassez de um (determinado por um conjunto de fatores), determina o limite de uso do outro fator, independente de quão atraente possa ser seu preço. Por isso, uma política de redução exógena da taxa de juros é, em geral, ineficaz aqui, mas não porque há armadilha de liquidez ou por conta do "limite inferior zero" da política monetária. O problema é que efetivamente esta política não exerce um efeito claro e bem determinado sobre a decisão de investimento, pois depende também de outros fatores que comumente afetam essas decisões nas abordagens heterodoxas, como o conjunto de instituições, para uns, a incerteza para outros e até heterogeneidade do capital para outros, que torna, em geral, não claramente determinada a curva de investimento agregado em relação à taxa de juros.

Portanto, não se pode contar estruturalmente com uma relação regular juros-investimento, independentemente de qualquer imperfeição ou rigidez de preço. Isto vai de encontro à recomendação (da HES) de políticas monetárias que corrijam eventuais distorções da taxa de juros em relação a um suposto nível natural, não apenas porque não é possível garantir que o investimento reagirá da forma esperada, mas porque a própria determinação da taxa natural com base numa curva de investimento "tradicional" fica desprovida de sentido.

Inconsistência 6 - estimular a demanda com aumentos da população e sua produtividade, mas não com a população atualmente desempregada

Conforme já mencionamos antes, a principal causa da estagnação do investimento, tanto segundo Summers, quanto segundo Hansen, se conecta diretamente com a baixa taxa de crescimento populacional somada à sua produtividade, ou seja $(n+b)$, conforme equação $(1)$, subentendendo que o crescimento da demanda está indissociável e proporcionalmente conectado com o crescimento da população e, o que é mais questionável ainda, que a demanda também aumenta com o aumento da produtividade do trabalho. Na verdade, isto por si só já revela uma inconsistência sem sequer sair dos próprios termos da HES. Dado que a população e a produtividade supostamente estimulam de alguma forma a demanda, não parece fazer sentido supor, ao mesmo tempo, que enquanto a economia estiver abaixo do pleno-emprego, a população ociosa não exerça nenhum estímulo sobre a demanda 
agregada. Se exercesse, o desemprego seria progressivamente eliminado por este estímulo, o que não é o caso. Contraditoriamente, os trabalhadores existentes não trouxeram demanda suficiente para chegar ao pleno-emprego, mas os que virão trarão mais demanda proporcional a seu aumento. Outrossim, uma economia abaixo do pleno-emprego, como afinal preconiza a HES, tenderia a reforçar diretamente a concepção heterodoxa (vista na inconsistência anterior) de que a restrição ao crescimento está no capital, não no trabalho, ficando cada vez mais difícil lidar com esta hipótese de que o crescimento exógeno da força de trabalho determina o investimento.

Inconsistência 7 - preconizar um crescimento liderado pela demanda, mas determinado por fatores de oferta

Ainda dentro deste cenário de crescimento da demanda agregada (e consequentemente da economia) estimulado pela própria população/produtividade, cabe pensar: mesmo que haja uma relação diretamente proporcional entre essas duas grandezas, não parece haver nenhuma justificativa concreta para que ambas cresçam à mesma taxa. Ou seja, notemos que os autores tratados estão impondo, sem maiores explicações, uma "solução" ad hoc para o primeiro problema de Harrod, diferente das que já vimos até aqui. Como $g_{k}$ e $g_{n}$ tenderiam a crescer à mesma taxa, quando isso ocorrer, esta também será a própria taxa de crescimento da economia. Esta suposta solução não deveria passar despercebida. Embora os canais de transmissão sejam suprimidos, a ideia básica para interpretar o primeiro problema deste jeito pode ser simplesmente sintetizada em:

$$
\begin{aligned}
& \uparrow(n+b), \uparrow Y, \uparrow I, \uparrow g \\
& \downarrow(n+b), \downarrow Y, \downarrow l, \downarrow g
\end{aligned}
$$

O que interessa ressaltar aqui é que, se a taxa natural de crescimento for exógena e se o crescimento da demanda efetiva, ainda que acompanhe a sua direção, for numericamente menor que esta taxa natural, ocorreria um nível de subutilização permanente da capacidade e uma taxa de desemprego crescente e explosiva. Já se a taxa natural for endógena, conforme vimos acima, isso não ocorreria e a taxa de desemprego tende a se estabilizar para uma dada taxa de crescimento da economia. Afinal, se supusermos que o crescimento é liderado pela demanda, não faz sentido limitálo, nem "para cima", nem "para baixo", por um fator de oferta, nesse caso o crescimento natural, que, por isso mesmo, é endógeno, não exógeno, nas teorias heterodoxas.

Vale lembrar neste ponto, que os modelos de crescimento liderado pela demanda existem em duas versões: investimento autônomo e investimento induzido. No caso do investimento autônomo é possível supor, por exemplo, que seu crescimento seja afetado pelo crescimento da produtividade do trabalho, mas não necessariamente que cresça na mesma proporção dessa última, estando sujeito, pela sua própria natureza, à interferência de uma série de circunstâncias e instituições. No caso do investimento induzido, que, nos modelos que o utilizam, é comumente induzido por gastos autônomos que não criam capacidade, é também possível supor que eventualmente o crescimento desses gastos autônomos possa ser afetado pelo crescimento exógeno da população como fazem alguns autores (por uma política específica de gastos do Estado de Bem Estar como em Allain (2018)), mas não pelo crescimento da produtividade. Mas em nenhum destes dois casos o investimento cresce a taxa natural e em nenhum dos dois casos a taxa natural de crescimento poderia ser totalmente exógena como na literatura sobre estagnação secular de Hansen e Summers. 
Inconsistência 8 - tornar o produto efetivo de longo prazo (secular) endógeno (liderado pela demanda) mas manter o produto potencial exógeno.

Até aqui já mostramos que a condição ( $i$ ) da HES, que já não se sustentava na análise marginalista, também parece não ser sustentável na abordagem heterodoxa do crescimento. Isto significa que o primeiro problema de Harrod se mostrou razoavelmente bem resolvido nas duas escolas. A condição (ii) da HES se mostrou possível na abordagem marginalista, mantendo determinados cenários restritivos. Cabe agora tratá-la na abordagem heterodoxa. Para decidir sobre qual linha de pensamento heterodoxa vamos fazer esta análise, consideramos essencial levar em conta a existência de gastos autônomos que não criam capacidade para o setor privado. Isto porque na versão da HES de Hansen e Summers, é admitida explicitamente não apenas a existência, mas sobretudo a função dos gastos do governo como forma de estimular e reativar a economia. Isto se dá via política fiscal em geral, podendo traduzir-se tanto como investimento público, que desloca para a direita a função investimento, quanto como consumo do governo, que desloca para a esquerda a função de poupança potencial. Nos dois casos é possível também deslocar, eventualmente, o investimento privado para a direita, via acelerador. De qualquer forma, trata-se de uma situação na qual um gasto autônomo adquire protagonismo, isto é, não surge apenas como mais um componente de demanda, mas como o componente de demanda recomendado para resolver o problema da estagnação. Como a linhagem de modelos do tipo supermultiplicador é aquela que incorpora este tipo de gasto autônomo no processo de crescimento liderado pela demanda dentro da heterodoxia, vamos analisar a HES com base nesse tipo de modelo.

A solução do segundo problema de Harrod via supermultiplicador gera uma tendência de longo prazo para o grau de utilização normal, como pretendia o próprio Harrod. Para isto, o ponto que faz a diferença é a parcela do investimento na renda (propensão marginal a investir) não ser exógena pois neste caso a capacidade produtiva nunca pode crescer mais rápido que a demanda, a fim de tornar possível o ajuste completo da primeira ao crescimento da segunda. Mas, por outro lado, se a propensão a investir aumentasse continuamente para tentar ajustar a utilização da capacidade ao nível normal, tenderia a tornar o modelo instável. O que elimina esta tendência à instabilidade no caso do supermultiplicador é a redução simultânea do consumo enquanto parcela da renda que ocorre enquanto a parcela do investimento aumenta. O mecanismo básico pelo qual tal coisa ocorre se dá exatamente através da inclusão do gasto autônomo entre os agregados macroeconômicos, ao mesmo tempo em que o investimento empresarial passa a ser inteiramente induzido. Incorporando isso aos objetivos deste texto, temos:

$$
\begin{gathered}
C=Z+c Y \quad(12)(\text { logo, } S=s Y-Z \text { (13) }) e \\
h=I / Y \quad(14)=\text { propensão a investir }=\text { parcela investida da renda. }
\end{gathered}
$$

Como a parcela investida da renda sempre gera, num modelo de crescimento liderado pela demanda, uma parcela poupada na mesma magnitude:

$$
h=I / Y=S / Y=s-Z / Y=\text { poupança média (15); }
$$

A causalidade ocorre de $h$ para $S / Y$. Quando $h$ aumenta, $Y$ aumenta e $Z / Y$ cai, aumentado a taxa de poupança média $(S / Y)$, ou seja, reduzindo o consumo enquanto parcela da renda. Observese que, neste modelo, a taxa de poupança média $(s-Z / Y$ ) é diferente da poupança marginal ( $s$ ) (ao 
contrário, por exemplo, do modelo de Harrod), justamente devido à presença do componente autônomo, Z. A partir daqui podemos notar inconsistências da HES quando analisada através deste modelo. Num modelo com inclusão deliberada de gastos autônomos entre os componentes de demanda, a "taxa garantida" da equação (1) precisa ser modificada. De fato, no caso do supermultiplicador, se $Y=Y^{*}$, a poupança potencial será

$$
S^{*}=\left(s Y^{*}-Z\right)
$$

e teríamos que reescrever a taxa garantida daquele como

$$
\frac{s-\frac{Z}{Y^{*}}}{v}
$$

que é o que, a rigor, deveria figurar no primeiro membro da equação (1).

Entretanto, não é usual neste modelo descrever uma taxa garantida de crescimento porque, como o crescimento é liderado pela demanda, a "taxa garantida" na verdade é endógena porque $Y^{*}$ agora é endógeno e (dado o gasto autônomo e a propensão a consumir) varia de acordo com $h$. Ironicamente, embora a causalidade seja diametralmente oposta, chegamos a uma situação semelhante àquela que analisamos no modelo de Solow: como a taxa garantida é endógena, a tendência gerada pelo modelo é que ela seja atingida, ou seja, isto simplesmente deixa de ser um problema. Só que enquanto no modelo de Solow a poupança potencial era exógena, no supermultiplicador ela é endógena, conforme se nota na equação (16) com $Y^{*}$ endógeno. A inconsistência com a condição (ii) da HES torna-se clara, pois não tem sentido dizer que o investimento cresce abaixo da poupança potencial se ele próprio eventualmente a determina. E é isso que deveria, afinal, acontecer num cenário em que é preconizada a centralidade da demanda e, em particular, dos gastos do governo para solucionar o problema da estagnação. A rigor, o próprio produto potencial é, em modelos deste corte, determinado pela evolução do investimento privado, que por sua vez, é fundamentalmente determinado pela evolução do produto efetivo, que por sua vez, segue o crescimento dos gastos autônomos. A colocação da pergunta-chave de Hansen e Summers como procurando solução para que o investimento se iguale à poupança potencial, já parte de uma imposição de que a oferta de recursos é que determina o tamanho possível da demanda e que o produto potencial é exógeno. ${ }^{10}$ Só isso já torna incoerente a tentativa de solução, de modo geral, heterodoxa deste problema, como um problema de crescimento econômico, logo de longo prazo. Uma solução via demanda para um problema de longo prazo, no qual se postula, por outro lado, que o produto potencial cresce liderado pela oferta não faz, enfim, sentido.

\section{Observações finais}

Nossa análise tornou possível compreender a razão de um paradoxo que podemos denominar "paradoxo de Gordon-Summers" (Summers, 2015; Gordon, 2015) no qual a queda de longo prazo da mesma variável, a taxa natural de crescimento (crescimento da população somado ao da produtividade do trabalho), é usada para justificar uma explicação da estagnação inteiramente baseada na oferta por

(10) A contradição acima aparece com clareza em passagens como esta onde Summers (2014, p. 37) fala que nesta situação "Perhaps Say's dubious law has a more legitimate corollary - "Lack of Demand creates Lack of Supply". In the long run, as the economy's supply potential declines." 
Gordon (que basicamente segue o modelo de Solow) e ao mesmo tempo uma outra baseada na demanda como a de Summers (e no passado a de Hansen). Este paradoxo fica esclarecido quando percebemos que Summers e Hansen utilizam a função de investimento neoclássica que, como apontado por Petri $(2013 ;$ 2015), só faz sentido (mesmo com capital homogêneo) a partir da posição de pleno-emprego, para analisar economias com desemprego persistente, nas quais estes autores consideram que o produto é determinado pela demanda.

Mostramos que não é possível conciliar as duas condições da hipótese de estagnação secular (e raras vezes sustentá-las isoladamente) nas abordagens que analisamos, isto é, tanto sob uma ótica neoclássica quanto heterodoxa.

Resumidamente, no que diz respeito à abordagem neoclássica vimos que os mecanismos de estagnação gerados sobre o investimento a partir da HES, como por exemplo uma baixa taxa de crescimento natural da população ou uma taxa de juros natural negativa, apresentam problemas teóricos que fazem com que não sejam capazes de explicar essa estagnação. Ou ainda, problemas na conciliação entre a estrutura teórica que ampara a HES com os próprios postulados da HES, como por exemplo estruturar a HES a partir da relação inversa investimento-juros e conciliá-la com a o postulado de desemprego estrutural, já que esta relação deveria ser construída sob pleno-emprego.

Já no que diz respeito à abordagem heterodoxa, concluímos, similarmente, uma incompatibilidade entre os postulados da HES e a estrutura teórica dos principais modelos heterodoxos aplicáveis. Por exemplo, a conciliação da complementaridade dos fatores de produção com uma taxa natural de juros, já que a última se tornaria irrelevante na ausência de substituição entre os fatores; ou a insustentabilidade de um gap entre poupança potencial e investimento quando o próprio produto/poupança potencial (e a taxa garantida de crescimento) deveriam ser endógenos ao processo de investimento.

Por fim, discutimos algumas hipóteses adicionais que pudessem ser úteis para justificar a HES, como acrescentar rigidez salarial para explicar o desemprego ou considerar que os gastos do governo, ou mesmo os investimentos privados, sejam parcialmente afetados pelo crescimento da população. Nenhuma das tentativas foi exitosa nesse sentido, ocasionando instabilidade harrodiana no primeiro caso e insuficiente poder explicativo, no segundo caso.

Concluímos que as proposições originais feitas por Hansen e Summers se tornam igualmente inaplicáveis e inconsistentes, seja para um modelo neoclássico, seja para um modelo heterodoxo. A tese de Gordon é mais coerente com os fundamentos neoclássicos. Não depende do uso incoerente da função investimento neoclássica num modelo onde o produto é determinado pela demanda, nem da hipótese de ad hoc de uma taxa natural de juros real negativa, discutível mesmo em termos neoclássicos. Mas, além das deficiências usuais da abordagem neoclássica, Gordon é forçado a ignorar a forte evidência empírica de histerese no produto e emprego tão bem documentadas na literatura recente (Girardi; Paternesi; Meloni; Stirati (2018)) e que, justamente, motivaram Summers a ressuscitar a HES. 
A Hipótese de Estagnação Secular nas teorias do crescimento econômico: um labirinto de inconsistências teóricas

\section{Bibliografia}

ALLAIN, O. Demographic growth, Harrodian (in)stability and the supermultiplier. Cambridge Journal of Economics, Feb. 2018.

CESARATTO, S.; SERRANO, F.; STIRATI, A. Technical change, effective demand and employment. Review of Political Economy, v. 15, n. 1, p. 33-52, 2003.

DELEIDE, M.; MAZZUCATO, M. Putting austerity to bed: technical progress, aggregate demand and the supermultiplier. UCL Institute for Innovation and Public Purpose, 2018. (Working Paper Series, 2018-01).

FAZZARI, S.; FERRI, P.; VARIATO, A. Demand-led growth and accommodating supply. 2017. (Working Paper). Available at: http://pages.wustl.edu/fazz/papers.

GIRARDI, D.; PATERNESI MELONI, W.; STIRATI, A. Persistent effects of autonomous demand expansions. Institute for New Economic Thinking, Feb. 2018. (Working Paper, n. 70).

GAREGNANI, P. Notes on consumption, investment and effective demand. Cambridge Journal of Economics, v. 2, p. 335-353; v. 3, p. 63-82, 1978-79. Reprinted in: Eatwell e Milgate (1983).

GORDON, R. Secular stagnation: a supply-side view. The American Economic Review, v. 105, n. 5, p. 54-59, 2015.

HARROD, R. An essay in dynamic theory. The Economic Journal, v. 49, n. 193, p. 14-33, 1939.

HARROD, R. Towards a dynamic economics. London: Macmillan, 1948.

HANSEN, A. H. Economic progress and declining population growth. The American Economic Review, v. 29, n. 1, p. 1-15, 1939.

LAVOIE, M. Post Keynesian economics: new foundations. Edward Elgar, 2014.

NAH, W.; LAVOIE, M. Convergence in a neo-Kaleckian model with endogenous technical progress and autonomous demand growth. 2017. Disponivel em: https://www.boeckler.de/pdf/v_2017_11_11_lavoie.pdf.

PETRI, F. The inevitable dependence of investment on expected demand: implications for neoclassical macroeconomics. In: LEVRERO, S. (Org.). Sraffa and the reconstruction of economic theory. 2013. v. 2, p. 44-67.

PETRI, F. Neglected implications of neoclassical capital-labour substitution for investment theory: another criticism of Say's law. Review of Political Economy, v. 27, n. 3, 2015.

SERRANO, F.; FREITAS, F. The Sraffian supermultiplier as an alternative closure for heterodox growth theory. European Journal of Economics and Economic Policy: Intervention, v. 14, n. 1, p. 70-91, 2017. DOI: 10.4337/ejeep.2017.01.06.

SERRANO, F.; FREITAS, F.; BHERING, G. The trouble with Harrod: the fundamental instability of the warranted rate in the light of the Sraffian supermultiplier. Metroeconomica, v. 70, n. 2, p. 263287, 2019. DOI: $10.1111 /$ meca.12230. 
SERRANO, F.; FREITAS, F.; BHERING, G. O supermultiplicador sraffiano, a instabilidade fundamental de Harrod e o dilema de "Oxbridge". Análise Econômica, v. 38, n. 77, 2019. DOI: /10.22456/2176-5456.7828.

SOLOW, R. A contribution to the theory of economic growth. The Quarterly Journal of Economics, v. 70, n. 1, p. 65-94, Feb. 1956.

SUMMERS, L. Reflections on the 'new secular stagnation hypothesis'. Secular stagnation: facts, causes and cures. VOXEU-CEPR, 2014. p. 27-38.

SUMMERS, L. Demand side secular stagnation. The American Economic Review, v. 105, n. 5, p. $60-65,2015$. 